\title{
EDITORIAL 2
}

\section{LAS CARTAS AL EDITOR: UNA NECESIDAD FISIOLÓGICA Y ONTOLÓGICA DE LAS REVISTAS CIENTÍFICAS}

\begin{abstract}
Adalberto Campo-Arias ${ }^{1}$
${ }^{1}$ Médico, Magister en salud sexual y reproductiva, Profesor auxiliar del programa de medicina. Universidad del Magdalena. Colombia. Correo: acampoa@unimagdalena.edu.co - http://orcid.org/0000-0003-2201-7404
\end{abstract}

\begin{abstract}
A la fecha, Duazary, Revista Internacional Ade Ciencias de la Salud ha publicado catorce volúmenes, 28 números regulares y un suplemento en trece años ininterrumpidos de divulgación científica nacional e internacional. Sin embargo, no se cuenta con la publicación de una carta al editor y ello se evidencia claramente en las publicaciones de los años más recientes en que está modalidad ha crecido notablemente ${ }^{1}$.
\end{abstract}

Las cartas al editor son publicaciones científicas en la que los lectores y autores de investigaciones originales interactúan: una necesidad fisiológica y ontológica para el desarrollo y crecimiento de las revistas, con la inclusión de editores, autores y lectores. El contenido o los temas que se abordan en las cartas al editor se relacionan directamente con las políticas editoriales de la publicación, de tal suerte que el contenido de la misma puede abarcar diversos temas ${ }^{2,3}$.

Por lo general, el emisor de la carta expresa puntos de vista, con frecuencia en desacuerdo, sobre el diseño o interpretación de los hallazgos de un trabajo publicado en un número anterior de la misma revista 4 . Las cartas al editor son tan importante como otro tipo de artículos publicados en las revistas científicas ${ }^{2}$. Dado que los autores de las investigaciones tienen el derecho, y casi están en la obligación, de responder, aclarar o controvertir sobre las opiniones expresadas por el emisor, en consecuencia, es un espacio en el que las publicaciones científicas permiten la discusión, el debate académico, tan necesario para el crecimiento o el desarrollo del conocimiento científico ${ }^{5}$.

Es importante anotar que en otras ocasiones las cartas al editor son informes cortos de trabajos de investigación de importancia o de casos; no obstante, la extensión de los mismos o lo preliminar de los hallazgos no suficientes para la publicación como una investigación original o una comunicación breve $e^{6-8}$. Asimismo, para estudiantes y profesionales de ciencias de la salud que inician una carrera en la investigación la publicación de una carta al editor puede representar un incentivo para continuar $y$ publicar en un futuro próximo un trabajo original ${ }^{6}$. Sin duda, esta experiencia temprana contribuiría a la construcción de una cultura de la divulgación y publicación científica desde los años de formación, al fortalecer a la autoeficacia para esta competencia ${ }^{9}$. Y será el primer escalón para ascender a las publicaciones internacionales y de esta manera hacer parte de la creciente internacionalización de las investigaciones biomédicas colombianas ${ }^{10,11}$, a pesar del pobre dominio del idioma inglés en todos los contextos de la vida en Colombia ${ }^{12}$. 
Las mejores cartas al editor se caracterizan por la brevedad y claridad; además, de ser constructivas y objetivas ${ }^{2}$. Usualmente, las cartas no pasan de 500 palabras; obstante la extensión es variable según la revista ${ }^{3}$. Las cartas al editor siguen una secuencia clásica, se comienza por el objetivo, lo más prudente es que sea único. Si el objetivo es comentar un trabajo publicado, por favor, destaque los puntos favorables, fortalezas o aportes de la investigación ${ }^{2,3}$. Seguidamente, señale los desacuerdos o limitaciones del estudio, con el respaldo de una referencia pertinente y robusta. Como otras publicaciones científicas, una carta al editor debe aportar algo al estado de conocimiento es un área por ello es necesario destacar la importancia de la carta para lograr publicación y hacerla atractiva para los lectores con la inclusión de una hipótesis novedosa o alternativa de interpretar o manejar los datos ${ }^{3}$. Las cartas al editor siempre incluyen referencias, casi siempre inferior a un número de $\mathrm{Cinco}^{2-4}$. Antes del envío es importante revisar las normas de la revista elegida y ajustar el documento a estas recomendaciones ${ }^{13}$.

A manera de conclusión, las cartas al editor es un tipo de artículo de divulgación científica hasta la fecha olvidado en Duazary. Puesto que estos artículos son importantes y enriquecen el debate académico, este editorial es una invitación a los lectores a que se animen enviar carta al editor para comentar algunos de los artículos originales publicados en el presente número, ganar confianza en la redacción científica y contribuir a la construcción de conocimiento mundial.

\section{REFERENCIAS BIBLIOGRÁFICAS}

1. Pérez-Anaya O, Ceballos-Ospino GA, GonzálezGálvez DM, Suescún-Arrogocés JD. Análisis bibliométrico de la revista Duazary en el quinquenio 2012-2016. Duazary. 2017; 14 (2): 122-30.
2. Girard NJ. Thoughts on writing a letter to the editor (editorial). AORN J. 2005; 81 (6): 1155-6.

3. Peh WC, Ng KH. Writing a letter to the Editor. Singapore Med J. 2010; 51 (7): 532-5.

4. Cano G. Cartas al editor (editorial). Colomb Med. 2006; 37 (2): 91.

5. Reyes CA. Recomendaciones para escribir un artículo científico. Medunab. 2001; 4 (12): 208-12.

6. Caballero-Ortiz AG. Cartas al editor como oportunidad de primera publicación en los miembros de FELSOCEM. CIMEL. 2014; 19 (2): 50.

7. Miyahira JM. La importancia de las cartas al editor (editorial). Rev Med Hered. 2010; 21: 57-8.

8. González de Dios J, González-Muñoz M, AlonsoArroyo A, Aleixandre-Benavent A. Comunicación científica (VII). Conocimientos básicos para elaborar un artículo científico (2): el fondo (lo que se dice). Acta Pediatr Esp. 2013; 71 (11): e358-63.

9. Gutiérrez C, Mayta P. Publicación desde el pregrado en Latinoamérica: importancia, limitaciones y alternativas de solución. CIMEL. 2003; 8 (1): 54-60.

10. Rosselli D. Latin American biomedical publications: the case of Colombia in Medline. Med Educ. 1998; 32 (3): 274-7.

11. Rincón CJ, Lasalvia P, Rosselli D. Ascenso de las publicaciones biomédicas colombianas (carta al editor). Rev Colomb Psiquiatr. 2016; 45 (4): 270.

12. Rosselli D. The language of biomedical sciences (letter). Lancet. 2016; 387 (10029), 1720-1.

13. Llanos G, Reyes CA. La alegría de publicar 4 . Los cien pecados de la presentación de artículos científicos. Colomb Med. 2002; 33 (3): 138-41. 